\title{
Effects and Mechanisms of Tapering in Maximizing Muscular Power
}

\author{
André Brännström, Anton Rova, Ji-Guo Yu \\ Sports Medicine Unit, Department of Surgical and Perioperative Sciences, Umeå University, 90187 Umeå, Sweden \\ *Corresponding Author: jiguo.yu@idrott.umu.se
}

Copyright $(0) 2013$ Horizon Research Publishing All rights reserved

\begin{abstract}
Muscle power is of great importance in most sports, and its development is one of the most fundamental physiological adaptations for improving physical performance. In order to optimize competition performance, athletes usually decrease training load before competition, the so-called tapering, to allow physiological and psychological recovery from accumulated training stress. Tapering could be conducted through changes in training volume, intensity and/or frequency, but training volume seems to be most effective in optimizing muscular power. There are two main types of tapering: progressive tapering and one-step tapering. Currently, there is no general conclusion on tapering duration. The physiological mechanisms regarding tapering effects on neuromuscular system are largely unknown. Generally, it is believed that sustained maximal muscular power after tapering is obtained through maintaining adaptations in muscle fiber size, fiber type and neural adaptations whereas increased maximal muscular power after tapering is assumed mainly through both physiological and psychological recovery. We believe that increased maximal muscular power after tapering may also rely on higher neural drive and increased muscle fiber cross sectional area (CSA), especially in type IIA muscle fibers. Complete rest is a special form of tapering and it usually only leads to sustained maximal power. This effect is believed to be associated with decreased muscle CSA and a transformation of muscle fibers from type IIA to type IIX.
\end{abstract}

Keywords Tapering, Complete Rest, Maximizing Muscular Power, Mechanisms

\section{Introduction}

The development of muscular power is one of the most fundamental physiological adaptations for improving physical performance. The ability to exert force earlier in a movement and throughout a greater range of motion is of great importance in most athletic movements [1]. These movements apply to most sports including sprinting, jumping, changing direction, throwing, kicking and striking
[2]. In order to optimize competition performance, athletes usually decrease training load before competition, the so-called tapering [3]. Even though many studies have been done on the topic, it is still unclear on issues like duration of the tapering, tapering speed and intensity. Furthermore, the underlying mechanisms of how tapering affects maximal neuromuscular power is not fully understood. In this review, we are going to take the recent studies on these issues into consideration and aiming to reveal 1) the general tapering methods used currently and 2) the effects of these tapering methods on maximal neuromuscular power and 3) the muscular and neurological mechanisms contributing to the adaptations in maximal neuromuscular power in tapering. Relevant publications were searched from database such as the US National Library of Medicine (PubMed) and Google Scholar. Search key words included: tapering, detraining, muscle fiber type, cross-sectional area (CSA), neuromuscular power, maximal power and different combinations of the key words.

\section{Tapering}

There are several definitions of tapering. According to Bosquet et al.[4], tapering is "... reductions in the training load of athletes in the final days before important competition, with the aim of optimizing performance." Another definition of tapering by Mujika[5] is "... a training phase before competition during which the training load is progressively reduced for a variable period of time to allow for physiological and psychological recovery from accumulated training stress, with the aim of maximizing competition performance."

Apparently, the essential of tapering is a decrease in training load through changes in training volume, intensity and/or frequency $[3,6]$. To make it easier to understand different tapering methods, tapering effects and potential mechanisms which will be introduced in the following parts, clear definition of each of the concepts involved in tapering definition seems very necessary. Training load is the total physical training performed (training stimulus) and is a combination of training volume, intensity and frequency. 
Training volume is defined as the total work done. In strength training, it is estimated by the product of sets and repetitions. Training frequency is the total number of training sessions performed for a given skill, task or body part per unit of time (typically per week). Training intensity is defined as percentage of maximal performance. In resistance training, it is often expressed as training repetition maximum (RM) [7].

The primary aim of tapering is to reduce the negative effects occurred under a training period and at the same time to recover and even to increase physiological capacity. Obviously the length of tapering period has to be taken into account as well. A proper combination of training load and duration of tapering will improve the adaptations obtained during training whereas improper tapering will lead to negative consequences by loss of training adaptations, the so-called detraining [3].

\subsection{Tapering Effects on Muscular Power}

There are two main types of tapering: progressive tapering and one-step tapering. Progressive tapering means the training load is reduced progressively or step by step whereas one-step tapering is that the training load is decreased to a predetermined level.

Currently, progressive tapering seems to be a more effective strategy to optimize performance before a competition [3]. Progressive tapering could result in increased maximal neuromuscular power. Collegiate swimmers performing progressive tapering through reduced training volume in a period of 3-5 weeks induced gains in maximal arm power, torque and swim performance [8]. Increase in maximal power was also shown in 14 collegiate field event athletes after a tapering phase following a training program of 4 phases, 4 weeks each [9], leading up to the NCAA championships. Tapering effects were even observed in single muscle fiber. Trappe et al.[10] observed that the contractile properties of single muscle fibers were largely increased in shortening velocity and absolute power.

One-step tapering could also induce increased maximal muscular power. Chtourou et al.[11] observed that 12 weeks of resistance training followed by 2 week one-step tapering with a reduction of $50 \%$ in training volume and an increase in intensity from $10 \mathrm{RM}$ to $8 \mathrm{RM}$ produced significant gains in leg maximal power. However, the effects of one-step tapering on neuromuscular power have been shown to be different in subjects with different training levels. After 2 week of resistance training followed by 1 week of one-step tapering, Häkkinen et al. [12] observed significant increase in maximal muscular power in 5 highly strength-trained athletes whereas in another 5 less well-trained subjects, no change in maximal muscular power was observed. This finding indicates that there is an individual variation in tapering period, depending on training level of the persons.

Table 1. Effects of tapering on maximizing muscular power

\begin{tabular}{|c|c|c|c|c|c|c|c|}
\hline Study, author (year) & Subjects & $\begin{array}{l}\text { Subject } \\
\text { backgrounds }\end{array}$ & Tests performed & $\begin{array}{l}\text { Duration } \\
\text { (weeks) }\end{array}$ & $\begin{array}{ll}\begin{array}{l}\text { Type } \\
\text { tapering }\end{array} & \text { of } \\
\end{array}$ & $\begin{array}{l}\text { Major findings } \\
\text { (Neuromuscular } \\
\text { power) }\end{array}$ & $\begin{array}{l}\text { Change in } \\
\text { loading }\end{array}$ \\
\hline $\begin{array}{l}\begin{array}{l}\text { Izquierdo et al. } \\
(2007)\end{array} \\
\end{array}$ & $\mathrm{n}=21$ & $\begin{array}{l}\begin{array}{l}\text { Basque } \\
\text { players }\end{array} \\
\text { pall } \\
\end{array}$ & CMJ, BP \& SQ & 4 & $\begin{array}{l}\text { TAP } \\
\text { progressive }\end{array}$ & $\leftrightarrow$ & $\begin{array}{l}\downarrow \text { volume, } \quad \uparrow \\
\text { intensity }\end{array}$ \\
\hline $\begin{array}{l}\text { Chtourou et al. } \\
(2012)\end{array}$ & $\mathrm{n}=31$ & $\begin{array}{l}\text { Physical } \\
\text { education } \\
\text { students } \\
\end{array}$ & $\begin{array}{l}\text { SJ, CMJ, MVC knee } \\
\text { ext. Wingate }\end{array}$ & 2 & $\begin{array}{ll}\text { One } \\
\text { taper }\end{array} \quad$ step & $\uparrow$ & $\begin{array}{l}\downarrow \text { volume } \\
\uparrow \text { intensity }\end{array}$ \\
\hline Coutts et al. (2007) & $\mathrm{n}=7$ & $\begin{array}{ll}\text { Elite } & \text { rugby } \\
\text { players } & \end{array}$ & $\begin{array}{l}\text { SQ \& BP, VJ, } 10 \text { \& } \\
40 \mathrm{~m} \text { sprint, Isok. } \\
\text { knee ext./flex. }\end{array}$ & 1 & $\begin{array}{l}\text { One } \\
\text { taper }\end{array}$ & $\leftrightarrow$ & $\begin{array}{l}\downarrow \text { volume } \downarrow \\
\text { intensity }\end{array}$ \\
\hline Trappe et al. (2001) & $n=6$ & $\begin{array}{l}\text { College } \\
\text { swimmers }\end{array}$ & $\begin{array}{l}\text { Swim bench, swim } \\
\text { power, } \\
\text { single fiber }\end{array}$ & 3 & Progressive & $\uparrow$ & $\downarrow$ volume \\
\hline $\begin{array}{l}\text { García-Pallarés et } \\
\text { al. (2010) }\end{array}$ & $\mathrm{n}=14$ & $\begin{array}{l}\text { Elite flat-water } \\
\text { kayak paddlers }\end{array}$ & BP \& PBP & 4 & Progressive & $\leftrightarrow$ & $\begin{array}{l}\downarrow \text { volume, } \\
\uparrow \text { intensity }\end{array}$ \\
\hline Trinity et al. (2006) & $\mathrm{n}=24$ & $\begin{array}{l}\text { Collegiate } \\
\text { swimmers }\end{array}$ & Arm ergometer & $3-4$ & Progressive & $\uparrow$ & $\downarrow$ volume \\
\hline $\begin{array}{l}\text { Santos EJ, Janeira } \\
\text { MA. (2009) }\end{array}$ & $\begin{array}{l}\operatorname{RT}(\mathrm{n}=8) \\
\operatorname{DTR}(\mathrm{n}= \\
7)\end{array}$ & $\begin{array}{l}\text { Adolescent } \\
\text { basketball players }\end{array}$ & $\begin{array}{l}\text { SJ, CMJ, abalakov } \\
\text { test, DJ, MP, MBT }\end{array}$ & 16 & $\begin{array}{l}\text { One } \quad \text { step } \\
\text { taper }\end{array}$ & $\leftrightarrow$ & $\begin{array}{l}\text { RT } \downarrow \text { volume } \\
\& \text { basketball } \\
\text { DTR only } \\
\text { basketball }\end{array}$ \\
\hline $\begin{array}{l}\text { Santos EJ, Janeira } \\
\text { MA. (2011) }\end{array}$ & $\begin{array}{l}\operatorname{RT}(\mathrm{n}=7) \\
\operatorname{DTR}(\mathrm{n}= \\
7)\end{array}$ & $\begin{array}{l}\text { Adolescent } \\
\text { basketball players }\end{array}$ & $\begin{array}{l}\text { SJ, CMJ, abalakov } \\
\text { test, DJ, MP, MBT }\end{array}$ & 16 & $\begin{array}{l}\text { One step } \\
\text { taper }\end{array}$ & $\leftrightarrow$ & $\begin{array}{l}\text { RT } \downarrow \text { volume } \\
\& \text { basketball } \\
\text { DTR only } \\
\text { basketball }\end{array}$ \\
\hline
\end{tabular}


Sustained muscular power could be observed after both progressive tapering and one-step tapering. Izquierdo et al. [13] reported that after 4 weeks progressive tapering with reduced training volume and increased intensity following 16 weeks of resistance training, the explosive muscular power obtained during the resistance training was sustained. To examine the effects of different levels of tapering Santos and Janeira[14] studied 2 groups of basketball players over 10 weeks of complex resistance training 2 times per week. Thereafter, the two groups performed different levels of tapering for 16 weeks of 1 training session per week: one group performed only regular basketball training and the other group performed regular basketball training and complex resistance training. The results showed both groups achieved similar increases in explosive strength after 10 week of training and maintained the obtained gains during the following tapering period. Similar results have been observed by Santos and Janeira[15]. Maintenance of maximal neuromuscular power has also been demonstrated in bench press and prone bench pull after 4 weeks of tapering following a combined resistance training and endurance training program [16]. Short period of one-step tapering could also result in maintenance of power obtained during training. In a previous study, a period of 7-day tapering with decreasing volume $(-55 \%)$ and frequency $(-17.4 \%)$ after 7 weeks resistance training and regular rugby training demonstrated a majority of power maintenance [17]. Some of the studies discussed in the study were briefly summarized in Table 1.

Rather than decreasing training load in tapering period, some studies observed the effects of increasing training load during tapering on muscular power/strength. Only one study reported increased maximal power by increasing training intensity during tapering whereas most studies available with increasing training intensity during tapering showed maintained maximal power.

Reduced training volume during tapering has been shown to be effective to achieve increases in maximal power [18] whereas training frequency was not manipulated in most studies. Increased maximal power has been shown after various periods of tapering. The duration of the tapering seems dependent on many factors such as reduced training extent, previous training level, fatigue status, and fitness level [18]. Usually the tapering period lasts 2 weeks or longer but shorter than 1 month. To our knowledge, no study has shown decreased maximal muscular power after tapering regardless of progressive or one-step.

\subsection{Mechanisms of Tapering Effects on Muscular Power}

Tapering could result in increased or maintained maximal muscular power. These changes could be due to either the muscular or/and the nervous system, similar as the neuromuscular adaptations occurred after resistance training.

In an early study Judge et al.[9] have observed in field event athletes that 4 week tapering resulting improvements in maximal power was accompanied by improvement in neural drive as indicated by increases in EMG amplitudes at onset of rapid isometric contractions. In another study by Häkkinen et al. [12]., resistance training followed by a period of one-step tapering ( 1 week) have also resulted in increased maximal power in leg extensors together with increased maximal neural activation. However, some of the test subjects demonstrated maintained maximal power and neural activation after the tapering. Importantly, the study demonstrated maintained CSA in quadriceps femoris in all of the subjects, indicating the importance of neural drive adaptation during tapering. However, in another study, resistance training resulted in increases in power production accompanied by increases in CSA in type IIA fibers, and the following progressive tapering produced no change in CSA in type I fibers, but the CSA in type IIA fibers was $11 \%$ larger compared to the value immediately after training [10]. The results indicate the importance of periphery muscular system adaptation in maximizing muscle power during tapering as suggested by Tortora and Derrickson[19].

In summary, the sustained maximal power after tapering is most likely obtained through maintaining the physiological adaptations in muscles including muscle fiber CSA, fiber type and/or neural adaptations whereas the increased maximal power after tapering is assumed to be due to both physiological and psychological adaptions. It is high likely that a higher neural drive and increased CSA in type IIA muscle fibers are responsible for the increased maximal power after tapering. Considering that currently not many studies have been performed on the topic, to make a definite conclusion of the mechanisms of tapering effects in muscular power is still too early.

\section{Complete Rest A Special Form of Tapering}

Complete rest can also be used as a kind of tapering. Complete rest means that the subjects are refrained from any type of physical training, but the normal daily activity is maintained. Complete rest as tapering is usually applied for a short period (up to several weeks) after very hard resistance training so that the subjects could fully recover from high physiological and psychological stress. Some studies label such periods as "detraining". However, typical detraining always leads to decrease or complete loss of the muscular adaptations acquired during training whereas complete rest as tapering often leads to sustained adaptations.

\subsection{Effects of Complete Rest on Muscular Power}

Complete rest may lead to increased, maintained or decreased maximal muscular power after either short or long periods of complete rest. In an early study by Izquierdo et al. [20], 4 week of complete rest following a long period of 
heavy resistance training resulted in a significant decrease in maximal strength.

Using a combination of tapering and complete rest, García-Pallarés et al. [16] observed that 4 weeks of tapering with reduced training load after 43 weeks of endurance training and resistance training resulted in maintained maximal strength. However, a subsequent 5 -week complete rest decreased maximal strength.

Complete rest could also result in maintenance of maximal power. In a previous study by Herrero et al. [21], 2 weeks of complete rest following 4 weeks plyometric training showed no difference in maximal power compared to post training levels. Similarly, neuromuscular strength was sustained after 2 weeks of complete rest in 12 power-lifters and American football players after an average of 8 years of strength training [22]. However, the muscular strength/power to complete rest may be various depending on the measuring methods. Terzis et al. [23] observed that 14 weeks of resistance training induced $6-12 \%$ increase in 4 different throwing tests and the achievements were maintained after a 4 weeks complete rest; however, a decrease in maximal strength in some parameters like squat, bench press and leg press has also been observed after the complete rest.
Similarly, after a relatively longer period of complete rest (3 months), maximal contractile muscle power as measured on a dynamometer was the same as post training values, but isometric strength was decreased to pre-training values [24].

Maintained performance in explosive jump was observed in both middle aged and elderly people after a long period (24 weeks) complete rest [25]. Maintained maximal power was also observed after short period (7 weeks) complete rest following short-sprint training on bicycle [26,27].

Interestingly, complete rest could induce increased maximal power. Andersen et al. [28] reported that 3 months of complete rest following 3 months resistance training resulted in increased maximal unloaded knee extension velocity and power; however, isokinetic muscle strength gains at slow and medium velocities returned to pre-training levels, which might attributed to the loss in gains of muscle CSA and increased electromyogram after the training. Currently, it is still unclear of the mechanisms of increased maximal power after long period of complete rest, and apparently further studies are needed on the topic. Some of the studies discussed in this section were briefly summarized in Table 2.

Table 2. Effects of complete rest on maximizing muscular power

\begin{tabular}{|c|c|c|c|c|c|}
\hline Study, author (year) & Subjects & Subject backgrounds & Tests performed & $\begin{array}{l}\text { Duration } \\
\text { (weeks) }\end{array}$ & $\begin{array}{l}\text { Major findings } \\
\text { (Neuromuscular power) }\end{array}$ \\
\hline Andersen et al. (2005) & $\mathrm{n}=14$ & Sedentary & Isok. \& maxv knee ext. & 12 & $\uparrow$ \\
\hline $\begin{array}{l}\text { Andersen \& } \\
(2000)\end{array} \quad$ Aagaard & $n=9$ & Sedentary & Isom./ dyn. knee ext. & 12 & $\leftrightarrow$ \\
\hline Terzis et al. (2008) & $\mathrm{n}=11$ & $\begin{array}{l}\text { Physical education } \\
\text { students }\end{array}$ & $\begin{array}{l}\text { Throwing exercises, SQ, } \\
\text { BP, LP }\end{array}$ & 4 & $\leftrightarrow$ \\
\hline Hortobágyi et al. (1993) & $\mathrm{n}=12$ & $\begin{array}{lr}\begin{array}{l}\text { Power } \\
\text { American } \\
\text { players }\end{array} & \text { football } \\
\end{array}$ & \begin{tabular}{|l|} 
Isom./conc./ecc. knee. \\
ext./flex. \\
BP, SQ, SJ, CMJ, DJ. \\
\end{tabular} & 2 & $\leftrightarrow$ \\
\hline $\begin{array}{l}\text { Linossier et al. (1997a), } \\
\text { Linossier et al. (1997b) }\end{array}$ & $\mathrm{n}=7$ & Sedentary & $\begin{array}{l}\text { Max cycling sprints to maxy } \\
\text { against increasing } \mathrm{Fb}\end{array}$ & 7 & $\leftrightarrow$ \\
\hline Herrero et al. (2006) & $\mathrm{n}=9$ & $\begin{array}{l}\text { Physical education } \\
\text { students }\end{array}$ & $\begin{array}{l}\text { 20-m sprint time, SJ, CMJ, } \\
\text { max. isom. sq }\end{array}$ & 2 & $\leftrightarrow$ \\
\hline Izquierdo et al. (2007) & $\mathrm{n}=14$ & Basque ball players & CMJ, BP \& SQ & 4 & $\downarrow$ \\
\hline Häkkinen et al. (2000) & $\mathrm{n}=14$ & \begin{tabular}{|lr} 
Middle & aged \& \\
elderly, & physically \\
active & \\
\end{tabular} & $\begin{array}{l}\text { Conc. knee ext. isom. knee } \\
\text { ext. SJ }\end{array}$ & 24 & $\leftrightarrow$ \\
\hline $\begin{array}{l}\text { García-Pallarés et al. } \\
(2010)\end{array}$ & $\mathrm{n}=7$ & $\begin{array}{l}\text { Elite flat-water kayak } \\
\text { paddlers }\end{array}$ & BP \& PBP & 5 & $\downarrow$ \\
\hline \multicolumn{6}{|c|}{$\begin{array}{l}\mathrm{BP}=\text { Bench press; } \mathrm{CMJ}=\text { Counter movement jump; Conc. = Concentric; } \mathrm{DJ}=\text { Drop jump; Dyn. = Dynamic; Ecc. = Eccentric; Ext. = } \\
\text { Extension; } \mathrm{Fb}=\text { Braking forces; Isok. = Isokinetic; Isom. = Isometric; } \mathrm{LP}=\text { Leg press; Max. = Maximal; Maxv = Maximal velocity; } \mathrm{PBP} \\
=\text { Prone bench pull; } \mathrm{SJ}=\text { Squat jump; } \mathrm{SQ}=\text { Squat; } \uparrow \text { indicates increased; } \leftrightarrow \text { indicates unchanged; } \downarrow \text { indicates decreased }\end{array}$} \\
\hline
\end{tabular}


From the discussions above it seems that complete rest could mainly result in sustained maximal power even though increased [28] and decreased maximal power [13,16] were also observed. Therefore, complete rest as a form of tapering seems not an optimal method when the goal is to increase maximal power. Since complete rest of both long and short period often leads to maintaining of maximal power, it seems to be more suitable for sports where maximal power is not critical, such as in most team sports.

\subsection{Mechanisms of Complete Rest on Muscular Power}

Complete rest as tapering can affect muscle fiber type composition. Many studies have shown that strength training could result in fiber type conversion from type IIX to type IIA [23,24,28]. However, if strength training is followed by a period of complete rest, an opposite conversion in fiber type could take place. Andersen and Agaard [23] showed that the amount of MHCIIX was markedly increased after 3 months rest following 3 months of resistance training. Increase in percentage of type IIX muscle fibers was also observed after 4 weeks of complete rest following a period of resistance training [22]; however, the authors failed to find evidence of a conversion between type IIA and type IIX fibers in power-lifters and American football players after two weeks resting. Interestingly, Linossier et al.[26] observed that after 7 weeks complete rest following a training regime of short-sprint cycling, the percentage of type IIB fiber was decreased while type IIB fiber CSA was highly increased

The duration of rest after resistance training seems to have an impact on muscle fiber type transformation. While 3 months [24,28] and 4 weeks [23] rest resulted in an increase in type IIX muscle fibers, a short period of 2 weeks complete rest did not lead to significant fiber type conversion between IIA and IIX [22].

Evidence has also shown that complete rest regardless of short or long period can affect muscle fiber size or CSA. Häkkinen et al.[25] showed that 24 weeks of complete rest resulted in reduced muscle fiber CSA to a level below the initial before training value. Similar results have been reported by Andersen et al.[28]. Complete rest induced decreases in muscle fiber CSA has been observed to be mainly in type II fibers and hardly in type I fibers [22,23]. However, previous studies have also shown unchanged muscle size as a result of a complete rest [22,24]. Yet, numerous studies have demonstrated that even though CSA was decreased after complete rest, maximal muscular power was sustained or even higher [22,23,25,28]. This was attributed to muscle fiber transformation from type IIA to type IIX during rest period [23,28], the later can generate higher power output than the former [29].

Complete rest could also affect gains in the nervous system. An increase in agonist EMG activity during maximal unloaded knee extension has been observed after 3 months of resistance training, which was decreased to pre-training levels after 3 months of rest [28]. However, Hortobágyi et al.[22] did not observe any significant changes in EMG activity after 2 weeks of complete rest in power lifters and American football players. As mentioned in the study, even though the subjects maintained performance after a period of complete rest, the subjects commented that they felt "unmotivated", "lazy" and "sluggish". Apparently, the psychological effects of tapering on muscular power should not be ignored.

\section{Conclusions}

The training load is obviously important in deciding the application of tapering or complete rest. Higher training load indicates greater neural and muscular adaptations; however, it also indicates higher level of fatigue and psychological stress, thus requiring a greater reduction in training load over a longer period [30]. The tapering allows dissipation of fatigue and the physiological systems to replenish themselves and even undergo "super compensation" [31]. On basis of the discussion above, we make the following conclusions.

1) Both progressive and one-step tapering are effective in increasing or maintaining maximal power.

2) Increased maximal power could be obtained after various periods of tapering.

3) Complete rest for both short and long periods mainly results in sustained maximal power.

4) The physiological mechanisms of tapering on maximizing muscular power are most likely associated with higher neural drive and increased CSA of type IIA muscle fibers.

5) The physiological mechanisms of complete rest on maintaining or decreased muscular power seem mainly to be associated with decreased muscle fiber CSA and fiber type transformation from type IIA to type IIX.

\section{Practical Suggestions for Optimum Tapering Effects}

To propose a detailed tapering protocol for a specific sport is difficult. Anyhow, on basis of the knowledge obtained from previous studies, we managed to make some general practical suggestions of tapering.

1) Progressive tapering could induce increased muscular power whereas one-step tapering is more suitable in sustaining muscular power obtained during resistance training.

2) The duration of tapering is usually 2 weeks or longer but shorter than 1 month.

3) The training load in progressive tapering never reaches ground level whereas the load decreasing speed depends on the tapering duration.

4) The training loading in one-step tapering is various but primarily around $50 \%$ of the resistance training load. 


\section{REFERENCES}

[1] S. J. Fleck, W. J. Kraemer. Designing resistance training programs. 3rd ed. Leeds: Human kinetics. 2004.

[2] P. Cormie, M. R. McGuigan, R. U. Newton. Influence of strength on magnitude and mechanisms of adaptation to power training. Med Sci Sports Exerc, Vol. 42, No. 8, $1566-81,2010$

[3] I. Mujika. Formtoppning i teori och praktik. Stockholm: SISU idrottsböcker - idrottens förlag. 2009.

[4] L. Bosquet, J. Montpetit, D. Arvisais, I. Mujika. Effects of tapering on performance: a meta-analysis. Med Sci Sports Exerc, Vol. 39, No. 8, 1358-65. 2007

[5] I. Mujika, S, Padilla, D. Pyne, T. Busso. Physiological changes associated with the pre- event taper in athletes. Sports Med, Vol. 34, No. 13, 891-927, 2004

[6] I. Mujika, S. Padilla. Scientific bases for precompetition tapering strategies. Med Sci Sports Exerc, Vol. 35, No. 7, 1182-7, 2003

[7] J. M. Wilson, G. J. Wilson. A Practical Approach to the Taper. Strength \& Conditioning Journal. Vol. 30, No, 2, 10-17, 2008

[8] J. D. Trinity, M. D. Pahnke, E. C. Reese, E. F. Coyle. Maximal mechanical power during a taper in elite swimmers. Med Sci Sports Exerc, Vol. 38, No. 9, 1643-9, 2006

[9] L. W. Judge, C. Moreau, J. R. Burke. Neural adaptations with sport-specific resistance training in highly skilled athletes. J Sports Sci, Vol. 21, No. 5, 419-27, 2003

[10] S. Trappe, D. Costill, R. Thomas. Effect of swim taper on whole muscle and single muscle fiber contractile properties. Med Sci Sports Exerc, Vol. 33, No. 1, 48-56, 2001

[11] H. Chtourou, A. Chaouachi, T. Driss, M. Dogui, D. G. Behm, K. Chamari, N. Souissi. The effect of training at the same time of day and tapering period on the diurnal variation of short exercise performances. J Strength Cond Res, Vol. 26, No. 3, 697-708, 2012

[12] K. Häkkinen, M. Kallinen, P. V. Komi, H. Kauhanen. Neuromuscular adaptations during short-term "normal" and reduced training periods in strength athletes. Electromyogr Clin Neurophysiol.Vol.31, No. 1, 35-42, 1991

[13] M. Izquierdo, N. A. Maffiuletti, J. García-López. Electromyostimulation and plyometric training effects on jumping and sprint time. Int J Sports Med, Vol. 27, No. 7, 533-9, 2006

[14] E. J. Santos, M. A. Janeira. Effects of reduced training and detraining on upper and lower body explosive strength in adolescent male basketball players. J Strength Cond Res, Vol. 23, No. 6, 1737-44, 2009

[15] E. J. Santos, M. A. Janeira. The effects of plyometric training followed by detraining and reduced training periods on explosive strength in adolescent male basketball players. J Strength Cond Res, Vol. 25, No. 2, 441-52, 2011

[16] J. García-Pallarés, L. Sánchez-Medina, C. E. Pérez, M. Izquierdo-Gabarren, M. Izquierdo. Physiological effects of tapering and detraining in world-class kayakers. Med Sci Sports Exerc, Vol. 42, No. 6, 1209-14, 2010

[17] A. Coutts, P. Reaburn, T. J. Piva, A. Murphy. Changes in selected biochemical, muscular strength, power, and endurance measures during deliberate overreaching and tapering in rugby league players. Int J Sports Med, Vol. 28, No. 2, 116-24, 2007

[18] L. Bosquet, J. Montpetit, D. Arvisais, I. Mujika. Effects of tapering on performance: a meta-analysis. Med Sci Sports Exerc, Vol. 39, No. 8, 1358-65, 2007

[19] G. J. Tortora, B. H. Derrickson. Principles of anatomy and physiology: Organization, support and movement, and control systems of the human body. 12th ed. Vol. 1. New York: Wiley cop. 2009

[20] M. Izquierdo, J. Ibañez, J. J. González-Badillo, N. A. Ratamess, W. J. Kraemer, K. Häkkinen, H. Bonnabau, C. Granados, D. N. French, E. M. Gorostiaga. Detraining and tapering effects on hormonal responses and strength performance. J Strength Cond Res, Vol. 21, No. 3, 768-75, 2007

[21] J. A. Herrero, M. Izquierdo, N. A. Maffiuletti, J. Garcia Lopez. Electromyostimulation and plyometric training effects on jumping and sprint time. Int J Sports Med, Vol. 27, No. 7, 533-9, 2006

[22] T. Hortobágyi, J. A. Houmard, J. R. Stevenson, D. D. Fraser, R. A.Johns, R. G.Israel. The effects of detraining on power athletes. Med Sci Sports Exerc, Vol. 25, No. 8, 929-35, 1993

[23] G. Terzis, G. Stratakos, P. Manta, G. Georgiadis. Throwing performance after resistance training and detraining. J Strength Cond Res, Vol. 22, No. 4, 1198-204, 2008

[24] J. L. Andersen, P. Aagaard. Myosin heavy chain IIX overshoot in human skeletal muscle. Muscle Nerve, Vol. 23, No. 7, 1095-104, 2000

[25] K. Häkkinen, M. Alen, M. Kallinen, R. U. Newton, W. J. Kraemer. Neuromuscular adaptation during prolonged strength training, detraining and re-strength-training in middle-aged and elderly people. Eur J Appl Physiol, Vol. 83, No. 1, 51-62, 2000

[26] M. T. Linossier, D. Dormois, A. Geyssant, C. Denis. Performance and fibre characteristics of human skeletal muscle during short sprint training and detraining on a cycle ergometer. Eur J Appl Physiol Occup Physiol, Vol. 75, No. 6, 491-8, 1997

[27] M. T. Linossier, D. Dormois, C. Perier, J. Frey, A. Geyssant, C. Denis. Enzyme adaptations of human skeletal muscle during bicycle short-sprint training and detraining. Acta Physiol Scand, Vol. 161, No. 4, 439-45, 1997

[28] L. L. Andersen, J. L. Andersen, S. P. Magnusson, C. Suetta, J. L. Madsen, L. R. Christensen, P. Aagaard. Changes in the human muscle force-velocity relationship in response to resistance training and subsequent detraining. J Appl Physiol, Vol. 99, No. 1, 87-94, 2005

[29] W. Scott, J. Stevens, S. A. Binder-Macleod. Human skeletal muscle fiber type classifications. Phys Ther, Vol. 81, No. 11, 1810-6, 2001

[30] L. Thomas, T. Busso. A theoretical study of taper characteristics to optimize performance. Med Sci Sports Exerc, Vol. 37, No. 9, 1615-21, 2005

[31] Y. Le Meur, C. Hausswirth, I. Mujika. Tapering for competition: A review. Science \& Sports, Vol. 27, No. 2, $77-87,2012$ 